LETTERS

\title{
Sinusoidal dilatation: a rare side effect of azathioprine
}

\author{
A M Jacobi, E Feist, B Rudolph, G R Burmester
}

Ann Rheum Dis 2004;63:1702-1703. doi: 10.1136/ard.2003.017855

$\mathrm{H}$ epatotoxicity is an often reported side effect of azathioprine treatment, which requires monitoring of serum transaminases and $\gamma$-glutamyltransferase $(\gamma$ GT), especially during the first 6 months of treatment. This case report, however, illustrates that side effects of azathioprine can also occur after a longer period of treatment. We report a case of sinusoidal dilatation as a rare side effect of azathioprine treatment in a patient with systemic sclerosis.

\section{CASE REPORT}

A 50 year old female patient with systemic sclerosis presented with a rapid increase of body weight (approximately $5 \mathrm{~kg}$ within 3 days) and abdominal circumference, diffuse abdominal pain, oedema of the lower extremities, dyspnoea, tachycardia, and low blood pressure $(90 / 60 \mathrm{~mm} \mathrm{Hg})$. Because systemic sclerosis with pulmonary involvement had been diagnosed $1 \frac{1}{2}$ years previously, the patient received azathioprine $(2 \mathrm{mg} / \mathrm{kg})$ and prednisone $(5 \mathrm{mg})$ daily. The patient tested positive for anti-PM/Scl (anti-exosomal) antibodies. Furthermore, protein $\mathrm{C}$ and S deficiency and occlusions of various finger arteries of the left hand were diagnosed. Therefore she has been treated with warfarin during the past 18 months and received intravenous iloprost intermittently. Treatment was tolerated without any side effects and 3 months before admission to the hospital clinical examination and laboratory measures were completely normal.

The laboratory tests at admission, however, disclosed a pancytopenia (leucocytes $2.04 \times 10^{9} / \mathrm{l}$, platelets $44 \times 10^{9} / \mathrm{l}$, erythrocytes $\left.2.02 \times 10^{12} / 1\right)$ increased $\gamma$-GT $(90 \mathrm{U} / \mathrm{l}($ normal $<38))$ and bilirubin $(38 \mu \mathrm{mol} / \mathrm{l}($ normal $<18))$, and signs of haemolysis with raised lactate dehydrogenase (323 U/l (normal <247)) and free haemoglobin. Liver function was only mildly impaired (antithrombin III 67\% (normal 70-130), pseudocholinesterase normal, slightly reduced albumin). Serum transaminases were moderately raised. Of note, there were no signs of any previous hepatic disease in the patient's history.

Ultrasound examination of the abdomen showed ascites; a thrombosis of the liver veins or portal vein was excluded. There were no characteristic signs of longstanding portal hypertension in the ultrasound examination (normal diameter of the portal vein and normal size of the spleen). However, ultrasonographic signs of liver steatosis were present. A computed tomographic scan of the abdomen showed fibrosis of the liver and a venous perfusion block.

Warfarin was replaced by heparin. Azathioprine was discontinued. After a mild diuretic treatment (40 mg furosemide and $25 \mathrm{mg}$ spironolactone/day), ascites completely disappeared within 3 days. A slight increase of haemoglobin, leucocyte, and platelet count and decrease of lactate dehydrogenase occurred spontaneously at the end of the first week of observation, whereas the $\gamma$-GT remained constant.

After the recovery of platelet counts, bone marrow and liver were biopsied. The histology showed left shifted granulopoiesis and erythropoiesis as well as megablastoid transformed erythrocytes and disturbed megakaryopoiesis. This is in line with bone marrow damage related to drug toxicity with signs of beginning regeneration. The liver tissue

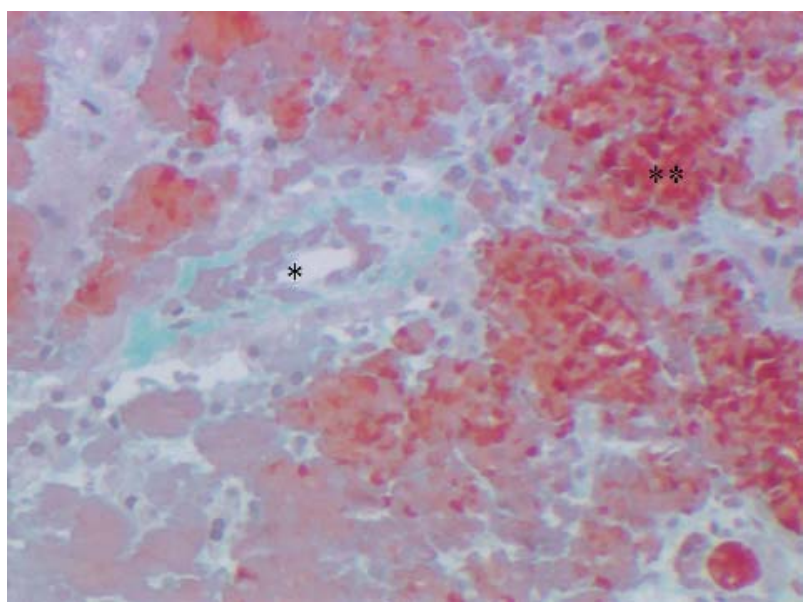

Figure 1 van Gieson's stained liver section. *Normal central venule; ${ }^{* *}$ sinusoidal dilatation with hyperaemia.

was free of inflammation and showed non-continuous infiltrative fibrosis without bridges or remodelling of the liver tissue. Signs of a venous block without central venulitis or clots were reported (fig 1). Sinusoidal dilatation was the predominant pathological finding.

\section{DISCUSSION}

Liver biopsy was performed to localise the venous perfusion block in more detail and to rule out Budd-Chiari syndrome, which had to be considered as a differential diagnosis. ${ }^{1}$ Sinusoidal dilatation and veno-occlusive disease (VOD) are vascular disorders of the liver associated with azathioprine treatment. Sinusoidal dilatation is assumed to be an early and less severe form of VOD, a liver disease also seen in patients after stem cell transplantation. ${ }^{2}$ In contrast with sinusoidal dilatation, VOD is characterised by additional affection of the central venules. ${ }^{3}$ Azathioprine possibly causes a depletion of glutathione in the endothelial cells. This mechanism has been described for murine sinusoidal endothelial cells. ${ }^{4}$ After endothelial injury subendothelial oedema causes congestion of sinusoids in a non-thrombotic manner. Sinusoidal dilatation has also been seen in patients after kidney transplantation. ${ }^{5}$ These patients had been receiving azathioprine for about 16-24 months before the onset of symptoms. After 1-3 years, fibrosis or micronodular cirrhosis had developed.

This case illustrates that also after longlasting treatment with azathioprine severe side effects may occur and, therefore, these patients should be continuously monitored.

\section{Authors' affiliations}

A M Jacobi, E Feist, G R Burmester, Department of Medicine, Rheumatology and Clinical Immunology, University Hospital Charité, Berlin, Germany

B Rudolph, Department of Pathology, University Hospital Charité, Berlin, Germany 
Correspondence to: Dr A M Jacobi, Department of Medicine/ Rheumatology and Clinical Immunology, University Hospital Charité, Schumannstr 20/21, 10098 Berlin, Germany; annett.jacobi@charite.de

Accepted 10 March 2004

\section{REFERENCES}

1 Bacon BR, Joshi SN, Granger DN. Ischemia, congestive failure, Budd-Chiari syndrome, and veno-occlusive disease. In: Kaplowitz N, eds. Liver and biliary diseases. Baltimore: Williams and Wilkins, 1992:421-31.
2 Kumar S, Deleve LD, Kamath PS, Tefferi A. Hepatic veno-occlusive disease (sinusoidal obstruction syndrome) after hematopoietic stem cell transplantation. Mayo Clin Proc 2003;78:589-98.

3 Weitz H, Gokel JM, Loeschke K, Possinger K, Eder M. Veno-occlusive disease of the liver in patients receiving immunosuppressive therapy. Virchows Arch A Pathol Anat Histol 1982;395:245-56.

4 DeLeve LD, Wang X, Kuhlenkamp JF, Kaplowitz N. Toxicity of azathioprine and monocrotaline in murine sinusoidal endothelial cells and hepatocytes: the role of glutathione and relevance to hepatic venoocclusive disease. Hepatology 1996:23:589-99.

5 Gerlag PG, Lobatto S, Driessen WM, Deckers PF, Van Hooff JP, Schroder E, et al. Hepatic sinusoidal dilatation with portal hypertension during azathioprine treatment after kidney transplantation. J Hepatol 1985; 1:339-48.

\section{Tick bite fever and arthritis associated with travel to Africa} T Ding, G Lloyd, H Tolley, A Bradlow

\section{CASE REPORT}

A 52 year old woman was admitted with fever and acute polyarthritis. She had visited a game reserve in Northern Province, South Africa 5 weeks before admission. Two weeks before admission she developed fever and flu-like symptoms, then mouth ulcers, and a non-itchy, maculopapular rash that covered her whole body and her scalp. Three days after the start of the rash she developed painful and swollen jointsnotably, the hands, elbows, wrists, knees, and feet.

On examination at admission she was apyrexial with no visible rash and no lymphadenopathy. She had florid synovitis at elbows, wrists, knees, and dactylitis affecting the right index finger (fig lA), left thumb, and left 4th toe. Spinal movement was normal. Examination was otherwise unremarkable.

The full blood count and renal function were normal, erythrocyte sedimentation rate $131 \mathrm{~mm} / \mathrm{lst} \mathrm{h}$ and $\mathrm{C}$ reactive protein (CRP) $324 \mathrm{mg} / \mathrm{l}$ (normal $<6 \mathrm{mg} / \mathrm{l}$ ). A chest radiograph, and $x$ ray examination of hands, feet, and sacroiliac joints were normal. A ${ }^{99 \mathrm{~m}} \mathrm{Tc}-\mathrm{MDP}$ bone scan showed increased uptake over the elbows, wrists, tarsi, left lst interphalangeal joint and 4th proximal interphalangeal joints, and right 2nd and 3rd metacarpophalangeal joints (fig 1B). Antinuclear antibodies, rheumatoid factor, HLAB27, hepatitis A and B, brucella, coxiella, chlamydia, parvovirus, and arbovirus serology were all negative, as was stool culture for salmonella, shigella, and campylobacter. It was confirmed that the patient's serum contained antirickettsia "spotted fever group" antibody, titre 1/640, by screening using sheep red blood cells sensitised with spotted fever group specific antigen in an immune-haemagglutination assay. ${ }^{1}$
Doxycline was started empirically before the rickettsial serology result was known, and continued for 3 weeks. Intramuscular depomedrone $120 \mathrm{mg}$ produced little improvement in joint symptoms and CRP. After 2 weeks sulfasalazine and oral prednisolone $15 \mathrm{mg}$ daily were started; marked and continuing improvement followed despite rapid tapering of the steroid dosage.

The incubation period of rickettsial disease is 1 to 2 weeks, followed by abrupt onset of malaise, headache, and fever. An eschar is sometimes visible at the site of tick bite. A maculopapular or petechial rash is present usually on days 7 to 10 after the bite.

\section{DISCUSSION}

African tick bite fever has been recognised since the beginning of the 20th century as a rural disease, contracted from ticks of cattle and game. Initially, the condition was thought to be exclusively due to Rickettsia conorii. The first human infection with $R$ africae was reported from Zimbabwe only in 1992. Recently R africae has also been identified in Amblyomma ticks from Niger, Mali, Burundi, and Sudan. ${ }^{2}$

Arthralgias occur commonly during rickettsial infections, but arthritis is rare and is usually acute aseptic monarthritis of a large joint. However, pauci- and polyarthritis have also been described. ${ }^{3}$ There have been 12 previous reports of arthritis with Mediterranean spotted fever, ${ }^{2}$ caused by $R$ conorii, and there has been only a single case report of arthritis associated with Rocky Mountain spotted fever. ${ }^{4}$ As far as we know, this is the first reported case of arthritis in association with spotted fever $(R$ africae and $R$ conorii) originating from South Africa.
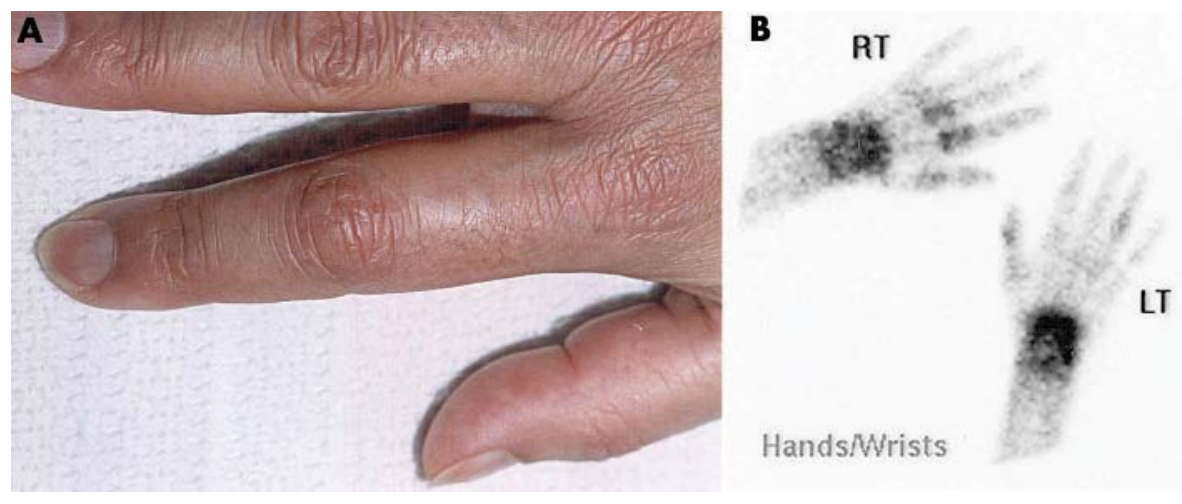

Figure 1 Dactylitis affecting the right index finger $(\mathrm{A})$ and ${ }^{99 \mathrm{~m} T \mathrm{~T}-\mathrm{MDP} \text { bone }}$ scan showing increased uptake over both wrists, left 1 st interphalangeal joint and 4 th proximal interphalangeal joints and right 2 nd and $3 \mathrm{rd}$ metacarpophalangeal joints (B). 
Between 1998 and 2002 spotted fever predominately due to $R$ africae was detected in 131 cases (four with arthralgia) returning from southern Africa to the UK. More cases may be seen world wide if southern Africa continues to develop as a tourist destination.

In conclusion, we have described a patient who developed polyarthritis owing to rickettsial disease acquired in South Africa. Diagnosis was made based on the clinical history and the presence of anti-spotted fever group antibodies. Rickettsial infection should be included in the differential diagnosis of acute aseptic arthritis in travellers returning from sub-Saharan Africas; effective treatment with tetracycline may otherwise be overlooked.

\section{Authors' affiliations}

T Ding, Department of Rheumatology, Nuffield Orthopaedic Centre, Windmill Road, Headington, Oxford OX3, 7LD, UK G Lloyd, H Tolley, CAMR, Porton Down, Salisbury, Wiltshire SP4 OJG, UK

A Bradlow, Department of Rheumatology, Battle Hospital, Oxford Road, Reading RG30 1AG, UK
We have no conflict of interest to declare. Dr Ding as corresponding author had full access to all the data in this case report and had final responsibility for the decision to submit for publication.

Correspondence to: Dr T Ding, tina.ding@doctors.org.uk

Accepted 7 April 2004

\section{REFERENCES}

1 Shirai A, Dietel JW, Osterman JV. Indirect hemagglutination test for human antibody to typhus and spotted fever group rickettsiae. J Clin Microbiolol 1975;2:430-7.

2 Cobeta-Garcia JC, Domingo-Morera JA. Mediterranean spotted fever and arthritis: comment on the article by Sundy et al. Arthritis Rheum 1996;39:2088.

3 Parola $\mathbf{P}$, Inokuma H, Camicas J-L, Brouqui P, Raoult D. Detection and identification of spotted fever group rickettsiae and ehrlichiae in African ticks. Emerg Infect Dis 2001;7:1014-17.

4 Sundy JS, Allen NB, Sexton DJ. Rocky mountain spotted fever presenting with acute monarticular arthritis. Arthritis Rheum 1996;39:175-6.

5 Raoult $D$, Fournier PE, Fenollar $F$, Jensenius $M$, Prioe $T$, de Pina JJ, et al. Rickettsia africae, a tick-bourne pathogen in travelers to sub-Saharan Africa. N Engl J Med 2001;344:1504-10.

\section{Extracorporeal shock wave therapy in the treatment of inferior calcaneal enthesophytosis: outcome by fan-beam dual $x$ ray absorptiometry (DXA)}

\section{R Cosentino, B Frediani, R De Stefano, C Acciai, S Manca, E Selvi, E Frati, R Marcolongo}

Ann Rheum Dis 2004;63:1704-1705. doi: 10.1136/ard.2003.013755

$\mathrm{P}$ lantar fasciitis with heel spurs is a common cause of heel pain, and is often not sensitive to conservative treatment, including insole supports, non-steroidal antiinflammatory drugs, local steroid injection, and physical therapy. ${ }^{12}$ In patients in whom conservative treatment fails, surgical intervention is recommended.

Recently, extracorporeal shock wave therapy has been introduced for the alleviation of painful heel and other conditions such as tennis elbow, calcifying tendinopathy of the shoulder, and non-union of fractures of the long bones. ${ }^{4-7}$

The presence and size of the heel spurs do not correlate with the clinical symptoms. ${ }^{48}$

Twenty patients aged between 40 and 70 years were treated. Exclusion criteria were degenerative diseases and/or inflammation of the ankle or foot joints, neurological abnormalities, nerve entrapment syndrome, pregnancy, infectious or neoplastic diseases, ulcerations, and bursitis.

Inclusion criteria were painful heel for a minimum of 12 months with heel spur radiologically examined and unsuccessful conservative treatment during the 6 months before referral to our hospital. No other treatment or drug was used during the 4 weeks before the trials began or during the study period, only the use of insole supports was permitted. An electrohydraulic system was used (Orthima; Direx Medical System Ltd).

Five treatments were given (one every 7 days), each treatment comprising 1200 shocks with a frequency of 120 shocks a minute. As the treatment may be initially painful, the energy density used on starting treatment was $0.03 \mathrm{~mJ} /$ $\mathrm{mm}^{2}$, which was gradually increased to $0.4 \mathrm{~mJ} / \mathrm{mm}^{2}$.

Variations in the bone mineral content (BMC) of enthesophytosis were evaluated by fan-beam dual $x$ ray absorptiometry (DXA) using a Lunar-Expert version 1.72, at baseline and 1 month after the end of treatment. ${ }^{9}$ This method allows rapid scanning of particular skeletal regions, and provides a radiographic-like image. ${ }^{10}$ Scans of $1 \mathrm{~mA}$ were applied to the heel, the foot was placed in complete extra-rotation, using a plastic support specific for a DXA evaluation of small bone structures. A region of interest was created in each patient, with a side at the base of the enthesophytosis, to include the enthesophytosis and to exclude the os calcis cortex; this region of interest remained unchanged for later controls (fig 1). The short term precision of the method was $0.5 \%$ (coefficient of variation) in vivo, as calculated in 10 patients scanned four times.

Pain levels were evaluated (before treatment, at the end of treatment, and 3 and 6 months later) by visual analogue scale (VAS) ranging from $0=$ no pain to $10=$ maximum pain,

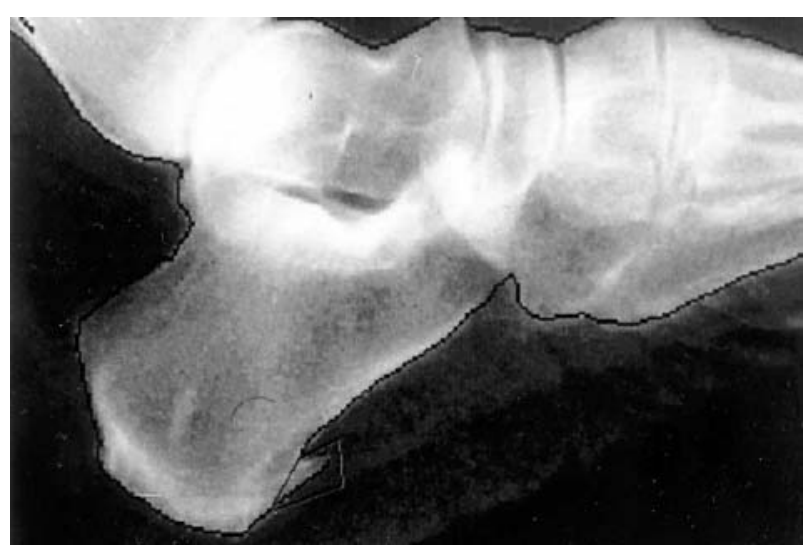

Figure 1 Fan-beam DXA of the heel. 
Table 1 Pain levels

\begin{tabular}{llll}
\hline & $\begin{array}{l}\text { Mean VAS at rest } \\
\text { (range 0-10) }\end{array}$ & $\begin{array}{l}\text { Mean VAS after walking } \\
\text { on awakening } \\
\text { (range 0-10) }\end{array}$ & $\begin{array}{l}\text { Mean VAS after normal } \\
\text { daily activity } \\
\text { (range 0-10) }\end{array}$ \\
\hline Basal & $8.1(1.5)$ & $8.1(1.4)$ & $8.3(1.2)$ \\
End of the treatment & $5.9(1.2)$ & $6.7(1.6)$ & $5.6(1.8)$ \\
After 3 months & $4.3(1.6)$ & $6.1(1.3)$ & $4.1(1.8)$ \\
After 6 months & $4.1(1.5)$ & $3.9(1.6)$ & $3.6(1.7)$ \\
\hline Results are shown as mean (SD). & &
\end{tabular}

at rest, after walking on awakening, and after normal daily activity. A significant decrease of VAS $(p<0.0001$, Wilcoxon test) was seen (table 1 ).

DXA analysis of enthesophytosis showed a significant decrease in BMC $(\mathrm{p}<0.001$, paired Student's $t$ test $)$ from an average of $0.162 \mathrm{~g}$ to a mean of $0.111 \mathrm{~g}$.

In conclusion, we found that extracorporeal shock wave therapy significantly improved the painful symptoms; in our study this reduction in pain was accompanied by a significant decrease of the BMC of the heel spur.

\section{ACKNOWLEDGEMENTS}

We thank Dr Silvia Manganelli for language assistance.

\section{Authors' affiliations}

R Cosentino, B Frediani, R De Stefano, C Acciai, S Manca, E Selvi, E Frati, R Marcolongo, Section of Rheumatology, University of Siena, Italy

Correspondence to: Dr R Cosentino, Institute of Rheumatology, Policlinico Le Scotte, 53100 Siena, Italy; r.cosentino@katamail.com

Accepted 22 February 2004

\section{REFERENCES}

1 Sobel E, Levitz SJ, Caselli MA. Orthoses in the treatment of rear foot problems. J Am Podiatr Med Assoc 1999;89:220-33.

2 Quinn M, Gough A. Ultrasound guided injection of plantar fasciitis. Ann Rheum Dis 1998;57:749-50.

3 Tomczak RL, Haverstock BD. A retrospective comparison of endoscopic plantar fasciotomy to open plantar fasciotomy with heel spur resection for chronic plantar fasciitis/heel spur syndrome. J Foot Ankle Surg 1995;34:305-11.

4 Cosentino R, Falsetti P, Manca S, De Stefano R, Frati E, Frediani B, et al. Efficacy of extracorporeal shock wave treatment in calcaneal enthesophytosis. Ann Rheum Dis 2001;60:1064-7.

5 Ko JY, Chen HS, Chen LM. Treatment of lateral epicondylitis of the elbow with shock waves. Clin Orthop 2001;387:60-7.

6 Cosentino R, De Stefano R, Selvi E, Frati E, Manca S, Frediani B, et al. Extracorporeal shock wave therapy for chronic calcific tendinitis of the shoulder: single blind study. Ann Rheum Dis 2003;62:248-50.

7 Schaden W, Fischer A, Sailler A. Extracorporeal shock wave therapy of nonunion or delayed osseous union. Clin Orthop 2001;387:90-4.

8 Schafer U, Micke O, Glashorster M, Rube C, Prott FJ, Willich N. The radiotherapy treatment of painful calcaneal spurs. Strahlenther Onkol 1995; 171:202-6.

9 Mazess R, Collik B, Trempe J, Barden H, Hanson J. Performance evaluation of a dual energy $x$-ray bone densitometer. Calcif Tissue Int 1989;44:228-32.

10 Lang T, Takada M, Gee R, Wu C, Li J, Hayashi-Clark C, et al. A preliminary evaluation of the lunar expert-XL for bone densitometry and vertebral morphometry. J Bone Miner Res 1997; 12:136-43.

\section{Clinical predictors of fetal and maternal outcome in Chinese patients with systemic lupus erythematosus}

\section{Y Mok, P Y Leung, T H Lao, Y Lo, T M Chan, W S Wong, C S Lau}

M aternal and fetal outcome of pregnancy in patients with systemic lupus erythematosus (SLE) depends very much on the composition of the patient cohort being analysed.

\section{METHODS AND RESULTS}

We performed a retrospective study to identify the clinical predictive factors for unfavourable pregnancy outcome in our Chinese patients with SLE from a homogeneous cohort being followed up at the university rheumatology clinic during the period 1982-96. Ninety one pregnancies from 66 patients were identified. Antiphospholipid antibodies (aPL), including lupus anticoagulant (LAC) and/or IgG anticardiolipin antibodies, were present in 18/66 (27\%) patients. In 33/80 (41\%) pregnancies resulting in live births, patients had a past history of lupus nephritis. Only one patient had impaired renal function, two had significant proteinuria $\geqslant 1 \mathrm{~g} /$ day, and four had stable hypertension while receiving antihypertensive drugs at conception. Active lupus was present within
6 months before conception in 12/91 (13\%) and at conception in $7 / 91(8 \%)$ pregnancies.

The live birth rate and fetal loss rate was $80 / 91$ (88\%) and $11 / 91$ (12\%), respectively. Fetal loss was found to be associated with serum anti-Ro $(\mathrm{p}=0.04)$, anti-La $(p=0.007)$, and significant proteinuria at conception $(p=0.03)$. aPL were not found to relate to a single episode of fetal loss $(p=0.06)$, but they were more prevalent in patients with recurrent miscarriages (odds ratio $(\mathrm{OR})=14.3$, $\mathrm{p}=0.008$ ), of which LAC was the strongest predictive factor $(\mathrm{OR}=23.3, \mathrm{p}=0.002)$. Poor fetal outcome was found in 27/ $80(34 \%)$ live births. There were 13 premature births and 14 fetuses had intrauterine growth retardation (IUGR). Significant proteinuria during pregnancy $(p=0.006)$ and flare in gestation $(p=0.001)$ was found to be related to prematurity. Multivariate analysis identified flare during pregnancy, in particular in the second trimester, as the strongest risk factor (relative risk $(R R)=5.5,95 \%$ confidence interval (CI) 1.4 to $21.9, \mathrm{p}=0.02$ ). Active lupus both within 
6 months before $(p=0.01)$ and at conception $(p=0.002)$ was found to predispose to IUGR. The latter was identified by multivariate analysis as the most predictive factor $(R R=22.1$, $95 \%$ CI 2.5 to $215.1, \mathrm{p}=0.008)$. Pre-eclampsia was present in $8 / 80(10 \%)$ pregnancies and no particular risk factor was found.

Thirty three pregnancies were recorded in the 27 patients with a past history of lupus nephritis. The live birth rate, fetal loss rate, and rate of poor fetal outcome (prematurity in four, IUGR in six) were not particularly different from those in patients with non-renal SLE and were $94 \%, 6 \%$, and $30 \%$, respectively. Predictive factors for poor fetal outcome in this subset of patients included significant proteinuria at conception $(p=0.004)$ and during pregnancy $(p=0.01)$ and active SLE within 6 months before conception $(p=0.007)$ and at conception $(p=0.03)$.

\section{DISCUSSION}

The fetal loss rate in our cohort lies near the lower end of the $11-46 \%$ range which was previously reported. ${ }^{1}$ This was partly because our patients had a lower prevalence of aPL $(27 \%)$ than the $34-44 \%$ reported in other cohorts ${ }^{2}$ and partly related to the small proportion of patients with active SLE at conception. Better live birth rates have been reported in patients with inactive rather than active disease at conception. $^{3-5}$ Our reported rate of poor fetal outcome and the associated risk factors were similar to those previously reported. ${ }^{16-9}$ The fetal loss rate in our patients with a past history of lupus nephritis was, however, lower than those reported $(13-46 \%)^{3}$ because the renal disease of our patients was quiescent at conception; active nephritis at conception has been reported to give a higher risk of fetal loss. ${ }^{10}$ Furthermore, patients in our clinic with impaired renal function were generally discouraged from becoming pregnant.

In conclusion, adverse pregnancy outcome was more common in patients with active disease in gestation. Fetal outcome is favourable in patients with a past history of lupus nephritis if they have normal renal function, no significant proteinuria, and satisfactory blood pressure control.

\section{Authors' affiliations}

M Y Mok, P Y Leung, Y Lo, T M Chan, W S Wong, C S Lau, Department of Medicine, Queen Mary Hospital, Pokfulam Road, Hong Kong T H Lao, Department of Obstetrics and Gynaecology, Queen Mary Hospital, Pokfulam Road, Hong Kong

Correspondence to: $\operatorname{Dr} M$ Y Mok, 4/F, Professorial Block Department of Medicine, Queen Mary Hospital Pokfulam Road, Hong Kong; mymok@ netvigator.com

Accepted 17 February 2004

\section{REFERENCES}

1 Out HJ, Derksen RH, Christiaens GC. Systemic lupus erythematosus and pregnancy. Obstet Gynecol Surv 1989;44:585-91.

2 Love PE, Santoro SA. Antiphospholipid antibodies: anticardiolipin and the lupus anticoagulant in systemic lupus erythematosus (SLE) and in non-SLE disorders. Ann Intern Med 1990;1 122:6892-98.

3 Haysleft JP, Lynn RI. Effect of pregnancy in patients with lupus nephropathy Kidney Int 1980; 18:207-20.

4 Houser MT, Fish AJ, Tagatz GE, Williams PP, Michael AF. Pregnancy and systemic lupus erythematosus. Am J Obstet Gynec 1980;138:409-13.

5 Tozman ECS, Urowitz MB, Gladman DD. Systemic lupus erythematosus and pregnancy. J Rheumatol 1980;7:624-32.

6 Mintz G, Niz J, Gutierrez G, Garcia-Alonso A, Karchmer S. Prospective study of pregnancy in systemic lupus erythematosus: result of a multidisciplinary approach. J Rheumatol 1986;13:732-9.

7 Rahman P, Gladman DD, Urowitz MB. Clinical predictors of fetal outcome in systemic lupus erythematosus. J Rheumatol 1998;25:1526-30.

8 Petri M, Allbritton J. Foetal outcome in lupus pregnancy; a retrospective case control study of the Hopkin's Lupus Cohort. J Rheumatol 1993;20:650-6.

9 Le Thi Huong DT, Wechsler B, Piette JC, Bletry O, Godau P. Pregnancy and its outcomes in SLE. Q J Med 1994;87:721-9.

10 Bobrie G, Liote F, Houillier P, Grunfeld JP, Jungers P. Pregnancy in lupus nephritis and related disorders. Am J Kidney Dis 1987;9:339-43.

\section{Temporomandibular joint pseudogout: an uncommon site for a familiar condition}

F Goldblatt, J Highton, G R Kumara

l: is well recognised that the temporomandibular joint (TMJ) may be affected by rheumatoid or psoriatic arthritides and ankylosing spondylitis. Interestingly, however, calcium pyrophosphate dihydrate (CPPD) crystal deposition is unusual in this site, and authors of several large case series of CPPD disease failed to report any acute attacks affecting this joint. ${ }^{12}$ As far as we are aware, only infrequent reports of CPPD crystal deposition in the TMJ have been published..$^{3-7}$ We therefore present the following case to highlight a possible differential diagnosis for patients presenting with TMJ pain and/or swelling.

\section{CASE REPORT}

A 57 year old man presented with an acute onset of severe pain and swelling affecting his right TMJ, on a background of chronic right sided TMJ discomfort. There were no associated systemic features. The patient had a past history of hypertension, hypercholesterolaemia, lumbar spine osteoarthritis, fifty (50) pack year smoking history, and an alcohol intake of $90 \mathrm{~g} /$ day. There was no previous history of gout or CPPD disease, and subsequent hand and knee $x$ ray investigations did not demonstrate chondrocalcinosis.

Clinical examination disclosed an uncomfortable, but otherwise well appearing man, with a warm tender swelling over his right TMJ associated with pain on attempting to open the joint. Blood investigations included a normal full blood count (haemoglobin $144 \mathrm{~g} / \mathrm{l}$, platelets $229 \times 10^{9} / \mathrm{l}$, white cell count $10.5 \times 10^{9} / 1$ ), C reactive protein $33 \mathrm{mg} / \mathrm{l}$ (normal 0-6 mg/l), normal electrolytes (including urate, magnesium, phosphate, calcium, and thyroid function), mild increase of alkaline phosphatase and $\gamma$-glutamyltransferase, normal iron studies, negative rheumatoid factor, positive antinuclear antibody (1/320 homogeneous pattern), negative extractable nuclear antigens, and negative antibodies to double stranded deoxyribonucleic acid. A plain radiograph of the right TMJ showed enlargement and irregularity of the right condylar head, confirmed by a computed tomography scan. In addition, synovial swelling around the TMJ, calcified loose bodies, articular sclerosis, and erosions were demonstrated. A joint aspirate comprised a thick, straw coloured fluid, and the 
patient proceeded to surgical irrigation of the upper and lower compartments of the joint to exclude septic arthritis. Synovial fluid analysis showed large numbers of leucocytes (up to $5.9 \times 10^{9} / 1$ and $70 \%$ polymorphs) and multiple weakly positive birefringent calcium pyrophosphate crystals. Gram stain and cultures were negative, thereby excluding infection.

The patient was treated with non-steroidal anti-inflammatory drugs (indometacin), with resolution of the acute inflammation. Mild restriction of movement and pain have persisted, secondary to underlying osteoarthritis, evident on magnetic resonance imaging. The patient continues to receive colchicine $0.5 \mathrm{mg}$ twice daily and presently is unaffected by features of CPPD disease in the TMJ or other joints.

\section{DISCUSSION}

Recognised as a distinct disease entity in the early 1960s, CPPD deposition disease has emerged as a heterogeneous disorder, with clinical presentations ranging from an acute arthritis to chronic pain secondary to degenerative cartilage disease. Although CPPD crystal formation remains incompletely understood, it is known to be influenced by a high ionic product (calcium $^{2+} \times$ inorganic pyrophosphate) and tissue promoters or inhibitors of crystal nucleation and growth. ${ }^{9}$ Prevalence increases with advancing age and the presence of metabolic/endocrine abnormalities, such as haemochromatosis, hypothyroidism, and hypomagnesaemia, none of which were present in our patient.

The knee is affected in over half of all acute attacks of CPPD disease, ${ }^{10}$ and as indicated by published reports, primary manifestation of CPPD arthropathy in the TMJ is relatively rare. ${ }^{3}$ Current available explanations do not clarify why the TMJ is so infrequently affected despite containing a fibrocartilage disc similar to that in the knee. It has been suggested that this may relate to the lack of clinical distinction between this entity and osteoarthritis of the TMJ and the infrequent pathological examination of TMJs. ${ }^{3}$ However, these explanations appear to simply imply an oversight of the condition and do not offer a pathophysiological reasons for the infrequent involvement.

An alternative proposal suggests that the peculiar anatomy of the adult TMJ, with its absence of hyaline cartilage in comparison with other diarthrodial joints, is an important contributor. ${ }^{3}$ Although the exact reason as to why the temporomandibular joint appears to be relatively "protected" from CPPD crystal deposition remains to be elucidated, clinicians should be alert to the possibility of its occurrence in this joint. In addition, this case highlights the importance of mandatory synovial fluid analysis for crystals in any acute undiagnosed arthritis, to facilitate prompt diagnosis and appropriate treatment.

\section{Authors' affiliations}

F Goldblatt, Department of Rheumatology, Repatriation General Hospital, Daw Park, South Australia, Australia

J Highton, Medical and Surgical Sciences, Dunedin School of Medicine, Dunedin, New Zealand

G R Kumara, Department of Stomatology, Dunedin School of Medicine, Dunedin, New Zealand

Correspondence to: Dr F Goldblatt, Department of Rheumatology, Repatriation General Hospital, Daw Park, 5041, South Australia; fgoldblatt@ hotmail.com

Accepted 8 February 2004

\section{REFERENCES}

1 McCarty DJ, Gatter RA. Pseudogout syndrome (articular chondrocalcinosis). Bull Rheum Dis 1964;14:331-4.

2 Bjelle A, Sunden G. Pyrophosphate arthropathy: a clinical study of 50 cases. $J$ Bone Joint Surg Br 1974;56:246-55.

3 Pritzker KPH, Philips H, Luk SC, Koven IH, Kiss A, Houpt JB. Pseudotumor of the temporomandibular joint: destructive calcium pyrophosphate dihydrate arthropathy. J Rheumatol 1976;3:70-81.

4 Good AE, Upton GL. Acute temporomandibular arthritis in a patient with bruxism and calcium pyrophosphate deposition disease. Arthritis Rheum 1982;3:353-5.

5 Zemplenyi J, Calcaterra TC. Chondrocalcinosis of the temporomandibular joint: a parotid pseudotumor. Arch Otolaryngol 1985;111:403-5.

6 Mogi G, Kuga M, Kawauchi H. Chondrocalcinosis of the temporomandibular joint: calcium pyrophosphate dihydrate deposition disease. Arch Otolaryngol Head Neck Surg 1987; 113:1117-19.

7 De Vos RAI, Brants J, Kusen GJ, Becker AE. Calcium pyrophosphate dehydrate arthropathy of the temporomandibular joint. Oral Surg 1981;51:497-502.

8 Kohn NN, Hughes RE, McCarty DJ, Faires JS. The significance of calcium phosphate crystal in synovial fluid of arthritic patients: the "pseudogout syndrome" II. Identification of crystals. Ann Interm Med 1962;56:738-45.

9 Wright GD, Doherty M. Calcium pyrophosphate crystal deposition I: not always "wear and tear" or aging. Ann Rheum Dis 1997;56:586-8.

10 McCarty DJ, Hogan JM, Gatter RA. Studies on pathological calcifications in human cartilage. J Bone Joint Surg Am 1966;48:309-25.

\title{
Antinuclear antibodies are common in an infectious environment but do not predict systemic lupus erythematosus
}

\author{
F Cainelli, C Betterle, S Vento
}

$\mathrm{T}$ he reasons underlying the appearance of autoantibodies are poorly understood. The recent proposal that childhood infections prevent both autoantibody formation and occurrence of autoimmune diseases ${ }^{12}$ led to the suggestion that widespread vaccination against infectious diseases might favour the development of autoimmune diseases. $^{2}$

To verify whether repeated infections from childhood prevent autoantibody formation we compared the prevalence of antinuclear antibodies (ANA), autoantibodies of infre- quent occurrence in healthy controls from Western Europe and associated with systemic lupus erythematosus (SLE) and other autoimmune diseases, in populations with different prevalence of infections throughout the course of lifenamely, African immigrants to Italy and Italians.

\section{METHODS AND RESULTS}

We obtained written informed consent from 137 Ghanaian or Nigerian apparently healthy immigrants to Italy and living in Verona (northeastern Italy), unrelated to patients with SLE 
Table 1 Prevalence of antinuclear antibodies (ANA) in Italian healthy controls, and in immigrants from West Africa to Italy according to age and length of residence in Italy

\begin{tabular}{llllll}
\hline & & \multicolumn{3}{l}{ Subjects who left Africa } & \\
\cline { 3 - 6 } & $\begin{array}{l}\text { Italian healthy } \\
\text { controls }\end{array}$ & $\begin{array}{l}\mathbf{3} \text { months- } \\
\mathbf{7} \text { years ago }\end{array}$ & $\begin{array}{l}\mathbf{8 - 1 4} \text { years } \\
\text { ago }\end{array}$ & $\begin{array}{l}\mathbf{1 5 - 2 1} \text { years } \\
\text { ago }\end{array}$ & $\begin{array}{l}\text { Total number } \\
\text { of Africa- } \\
\text { born subjects }\end{array}$ \\
\hline Number & 375 & 68 & 42 & 14 & 124 \\
Age, mean (SD) & $30(15)$ & $31(7)$ & $38(6)$ & $45(5)$ & $35(8)$ \\
ANA positive, No (\%) & $13(3.5)$ & $24(35)$ & $8(19)$ & $2(14)$ & $34(27)$ \\
Reciprocal ANA titres, & $40(0-160)$ & $80(40-320)$ & $40(40-160)$ & $40(40)$ & $40(40-320)$ \\
median (range) & & & & & \\
\hline
\end{tabular}

or other autoimmune diseases, characterised by ANA positivity. We drew blood samples which were first tested for anti-HIV antibodies. Thirteen positive subjects were excluded from the survey. In the remaining 124 (mean age 35 , range $8-53$ years; 58 women) we looked for the presence of ANA by immunofluorescence on Hep-2 cells. We selected anti-HIV negative subjects to exclude the influence of antiHIV antibody cross reactivity or HIV infection itself on the results of ANA determination; we also excluded relatives of patients with ANA positive autoimmune diseases because ANA positivity is more common in this subgroup. ${ }^{34}$

All the subjects studied recalled at least four episodes of malaria and three episodes of diarrhoea of at least 5 days' duration. Hence the immigrant study population had been exposed to repeated infections during their lifetime. The prevalence (reciprocal titres 40-320) of ANA was found to be very high $(27.4 \%$, comparable to that of relatives of white patients with SLE) ${ }^{4}$ and even higher in more recent immigrants (table 1). Of the 34 positive subjects, 17 were women and 17 men; their mean (SD) age was 33 (8). As a control population, we used 375 white northeastern Italian subjects matched for age and sex and found an ANA prevalence of $3.5 \%(\mathrm{p}<0.01)$.

\section{DISCUSSION}

Our data strongly suggest that living in an "infectious" environment from early life does not prevent, but rather favours, the formation of ANA. Although the reasons underlying their appearance are obscure, a role for a molecular mimicry between nuclear components of normal cells and parasitic or viral antigens cannot be excluded, as this has been demonstrated with the hepatitis B virus DNA polymerase. $^{5}$

The finding that ANA positivity is far higher in recent immigrants is intriguing, as they are younger and therefore expected to have a lower incidence of autoantibodies than older subjects. Furthermore, although ANA are more frequently detected in women, we did not observe a preponderance in the female immigrant population tested. Although a definitive demonstration would require repeated testing of immigrants and demonstration of loss of ANA positivity over time, the present findings do suggest that the longer a person lives in a "less infectious" environment, the higher is the probability that they will be autoantibody negative.

Interestingly, none of the ANA positive subjects have developed any symptoms of autoimmune diseases in a mean follow up of 18 months.

In conclusion, our data demonstrate that markers of autoimmunity, such as ANA, are frequently found in Africa-born people but tend to be lost if they live for a long time in Western countries. Their presence should not therefore be regarded as predictive of SLE, a conclusion which confirms findings from studies in developed countries. ${ }^{6}$

Prospective epidemiological studies are needed both in developed and developing countries if the real mechanisms leading to overt autoimmune diseases are to be understood. Meanwhile, vaccination programmes in developing countries can continue without any concerns about a possible increase in the incidence of autoimmune diseases.

\section{Authors' affiliations \\ F Cainelli, S Vento, Department of Pathology, University of Verona, Verona, Italy \\ C Betterle, Clinical Immunology and Allergy, Department of Medical and Surgical Sciences, University of Padua, Padua, Italy}

Correspondence to: Dr F Cainelli, Via Vasco de Gama 7, 37138 Verona, Italy; francescacainelli@yahoo.it

Accepted 16 February 2004

\section{REFERENCES}

1 Zinkernagel RM. Maternal antibodies, childhood infections, and autoimmune diseases. N Engl J Med 2001;345:1331-5.

2 Bach JF. The effect of infections on susceptibility to autoimmune and allergic diseases. N Engl J Med 2002;347:911-20.

3 Sato El, Atra E, Gabriel A Jr, Masi AT. Systemic lupus erythematosus: a family study of 25 probands. Clin Exp Rheumatol 1991;9:455-61.

4 Corporaal S, Biil M, Kallenberg CG. Familial occurrence of autoimmune diseases and autoantibodies in a Caucasian population of patients with systemic lupus erythematosus. Clin Rheumatol 2002;21:108-13.

5 Gregorio GV, Choudhuri K, Ma Y, Vegnente A, Mieli-Vergani G, Vergani D. Mimicry between the hepatitis B virus DNA polymerase and the antigenic targets of nuclear and smooth muscle antibodies in chronic hepatitis B virus infection. J Immunol 1999; 162:1802-10.

6 Shmerling RH. Autoantibodies in systemic lupus erythematosus - there before you know it. N Engl J Med 2003;349:1499-500. 